\title{
O PROBLEMA DAS AÇÕES AFIRMATIVAS NO BRASIL E O MITO DA DEMOCRACIA RACIAL
}

\author{
Paulo Henrique Muniz ${ }^{1}$
}

\begin{abstract}
Resumo:
O presente trabalho tem por objetivo discutir a aplicação das ações afirmativas como forma de promover a igualdade material entre os cidadãos brasileiros, garantido-lhes o acesso a educação, saúde, emprego digno, ascensão social e econômica, promovendo o resgate da dignidade, passando pelo reconhecimento do racismo culturalmente enraizado que contratas com o mito da democracia racial.
\end{abstract}

Palavras-chaves: Ações Afirmativas, Princípio da Igualdade, Direito Constitucional Brasileiro.

\begin{abstract}
:
The following paper intends to debate the application of affirmative action how way to promote the essential equality among brazilians citizens, keeping save the access to education, health, condign employment, social and economical ascension, promoting the ransom of dignity, crossing for the admission of the racism rooted in the culture that fight against the myth of racial democracy.
\end{abstract}

Key-words: Affirmative Action, Equality Principle, Brazilian Constitutional Law.

\section{INTRODUÇÃO}

No ano 2000 emergiu no cenário nacional a discussão acerca da necessidade ou não da implementação de ações afirmativas no Brasil isso ficou claro com as manifestações populares seja de indignação, ou dos aplausos com relação a política adotada pelo Estado do Rio de Janeiro em reservar cotas raciais nas universidades públicas. Porém, a discussão é bem mais complexa que isso. A adoção das cotas nos remete obrigatoriamente a uma análise do processo de formação da sociedade brasileira, bem como, a uma profunda reflexão acerca de questões pontuais tais como: racismo, desigualdade social e outras que maculam a história brasileira.

\footnotetext{
${ }^{1}$ Possui graduação em História pela Universidade Estadual do Oeste do Paraná (2003) e graduação em Direito pela Universidade Paranaense (2008). especialização em Direito Aplicado pela Escola da Magistratura do Paraná (2009) e especialização em Direito Previdenciário pela União Educacional de Cascavel (2012). especialização em Filosofia Política e do Direito pela Universidade Estadual do Oeste do Paraná (2015), atualmente é Mestrando em Ciências Sociais pela Universidade Estadual do Oeste do Paraná e atua profissionalmente como Analista Judiciário do Tribunal de Justiça do Estado do Paraná.
} 


\title{
2. CONCEITO DE AÇÕES AFIRMATIVAS
}

As ações afirmativas são políticas compensatórias que opõem-se as desigualdades sociais que não derivam imediatamente de distinções de renda e de propriedade (patrimonial), sendo até certo ponto externas a lógica do mercado, porém, capazes de influir decisivamente em seu funcionamento e nos seus resultados.

\begin{abstract}
A expressão "ação afirmativa" foi usada pela primeira vez numa ordem executiva (decreto) federal norte-americana de 1965, onde se estabelecia que as empresas empreiteiras que haviam sido contratadas por parte das entidades públicas ficavam obrigadas a uma ação afirmativa, qual seja, com objetivo de fazer crescer a contratação dos grupos que eram considerados minorias, desigualados socialmente e, por conseguinte juridicamente. ${ }^{2}$
\end{abstract}

A partir desse momento passou-se a atribuir o significado de exigência de favorecer algumas minorias socialmente marginalizadas, ou juridicamente desigualadas por preconceitos enraizados culturalmente. As ações afirmativas têm o propósito de alcançar a eficácia do princípio da igualdade consagrado constitucionalmente.

Portanto, as ações afirmativas de forma imediata combatem os efeitos acumulados em virtude de discriminações ocorridas no passado e no presente. Dessa forma, nada mais são do que a implementação da igualdade material.

Uma das principais definições de ação afirmativa foi a formulada por Joaquim Barbosa Gomes, Ex-Ministro do Supremo Tribunal Federal segundo o qual:

\begin{abstract}
Ações afirmativas se definem como políticas públicas (e privada) voltadas à concretização do princípio constitucional da igualdade material e à neutralização dos efeitos da discriminação racial, de gênero, de idade, de origem nacional e de compleição física. Na sua compreensão, a igualdade deixa de ser simplesmente um princípio jurídico a ser respeitado por todos, e passa a ser um objetivo constitucional a ser alcançado pelo Estado e pela sociedade. ${ }^{3}$
\end{abstract}

Desses conceitos pode-se extrair as seguintes características das ações afirmativas: "São iniciativas ou políticas que podem ser adotadas, incentivadas ou impostas pelo Estado para garantir os direitos fundamentais, reduzir as desigualdades sociais, e atingir o bem

\footnotetext{
${ }^{2}$ ATCHABAHIAN, Serge. Princípio da Igualdade e Ações Afirmativas. São Paulo: RCS Editora, 2004, p. 167.

${ }^{3}$ GOMES, Joaquim Barbosa e SILVA, Fernanda Duarte Lopes Lucas da. Ações Afirmativas e os Processos de Promoção da Igualdade Efetiva. Seminário Internacional - As Minorias e o Direito. Série Cadernos CEJ 24, p. 20. Disponível em: http://w3.ufsm.br/afirme/ARTIGOS/variados/var02.pdf, acesso em: 28/11/2009.
} 
comum". ${ }^{4}$ Sendo direcionadas a grupos "(que podem ser classificados em função de suas características biológicas como raça, sexo, idade e deficiência, ou sociais como renda, origem, ou religião)" ${ }^{, 5}$ que encontram-se em desvantagem no acesso aos direitos fundamentais, subsistindo até que sejam cessadas as condições de desigualdade que motivaram sua criação.

"A adoção de cotas pode ser entendida como uma ação emergencial, ou paliativa." " Considerando o histórico de lutas sociais das minorias na sociedade brasileira, a reserva de cotas apresenta-se como a eclosão de um processo de sucessivas conquistas rumo assecuramento de garantias mínimas de igualdade e dignidade e, por conseguinte, de cidadania a todos os brasileiros.

No Brasil as primeiras ações afirmativas surgiram com a Consolidação das Leis do Trabalho, e se intensificaram com a adesão às convenções e acordos internacionais que defendem o respeito aos direitos humanos fundamentais, a não discriminação, e a igualdade. $^{7}$

Um marco que intensificou as pressões externas e internas sobre o Brasil em razão da exclusão social em que vive uma parcela considerável da população foi a III Conferência Mundial contra o Racismo, a Discriminação Racial, a Xenofobia, e Formas Correlatas de Intolerância realizada em Durban. ${ }^{8}$

A partir daí intensificaram-se as discussões sobre as políticas de ações afirmativas para restabelecer a justiça social e o atendimento dos direitos humanos para a maioria dos brasileiros, em especial através da criação do Conselho Nacional de Combate à Discriminação (CNCD), no âmbito da Secretaria de Estado dos direitos Humanos do Ministério da Justiça, a qual tem em seus objetivos a promoção da igualdade e proteção dos direitos de grupos sociais e étnicos afetados por discriminação racial e intolerância.

Até 2009 já haviam sido propostos mais de 40 projetos de lei no Congresso Nacional tratando sobre a reserva de vagas no ensino superior em instituições públicas como direito à inclusão social, entre eles pode-se destacar o projeto de Lei 73/1999, bem como o projeto de Lei 3198/2000, chamado de Estatuto da Igualdade Racial, de autoria do Deputado

\footnotetext{
${ }^{4}$ SANTIAGO, Nestor Eduardo Arruna. NORBERTO, Aurilena Pereira. RODRIGUES, Sandra Maria Coelho. Direito à inclusão: implantação de políticas de ações afirmativas na IES públicas brasileiras - experiência na UFC. Pensar, v.13, n.1, Jan/Jun, 2008, p. 138. Disponível em: http://www.unifor.br/notitia/file/2554.pdf, acesso em: 28/11/2009.

${ }^{5}$ Ibid., p 138.

${ }^{6}$ Ibid., p 147.

${ }^{7}$ Ibid., p. 137.

${ }^{8}$ III Conferência Mundial Contra o Racismo, Discriminação Racial, Xenofobia, e Intolerância Correlata Durban, África do Sul, 31 de agosto a 08 de setembro de 2001.
} 
Paulo Paim, que cria cotas raciais. Mesmo sem a aprovação da maioria dos mencionados projetos abriram-se diversos debates quanto a sua necessidade. ${ }^{9}$

Em 13 de Maio de 2003 foi criado por decreto presidencial o Programa Nacional de Ações Afirmativas com o objetivo de implementar uma série de medidas específicas no âmbito da administração pública federal que privilegiassem a participação de afrodescendentes, mulheres e portadores de deficiência.

Na última década, o governo brasileiro tem colocado em prática a adoção de políticas públicas para universalização e democratização da educação. “Através de medidas variadas como o aumento da oferta de vagas, criação de novos cursos, financiamento de estudos, programas de assistência estudantil, estímulo de ensino à distância e políticas de cotas para ingresso". ${ }^{10}$

Principalmente, porque a "educação é direito fundamental e tendo em vista o valor do capital humano na sociedade do conhecimento"11 e da informação.

O governo do Presidente Luiz Inácio Lula da Silva, deu ênfase ao tema inclusão e a adoção de políticas de ações afirmativas em todas as áreas. Dentre as quais destacam-se a criação de diversas secretarias especiais (Secretaria Especial de Direitos humanos - SEDH, Secretaria Especial de Políticas de Promoção da Igualdade Racial - SEPPIR, Secretaria Especial de Políticas para as Mulheres - SPM, Secretaria de Educação Continuada, Alfabetização e Diversidade - SECAD/MEC), a regularização de terras indígenas e de quilombolas e diversos programas. $^{12}$

$\mathrm{Na}$ área de educação especificamente tem articulado iniciativas com o intuito de promover a equidade de acesso e garantir a permanência dos alunos dos grupos identificados como excluídos. "Como exemplo pode-se citar os programas de assistência ao estudante (PAE, PROUNI, FIES), criação UAB (Universidade Aberta do Brasil), programas para diversidades étnicacultural (Programa Diversidade na Universidade), entre outros."13

Desde 1968 o Brasil figura como signatário de três importantes tratados internacionais, quais sejam: a Convenção 111 da Organização Internacional do Trabalho (OIT), concernente à Discriminação em Matéria de Emprego e Profissão (1968); a Convenção Relativa à Luta Contra a Discriminação no Campo do Ensino (1968); a Convenção

\footnotetext{
${ }^{9}$ SANTIAGO, Nestor Eduardo Arruna. NORBERTO, Aurilena Pereira. RODRIGUES, Sandra Maria Coelho. Op. cit, p 137.

${ }^{10}$ Ibid.

${ }^{11}$ Ibid.

${ }^{12}$ Ibid., p 141.

${ }^{13}$ Idem.
} 
Internacional sobre a Eliminação de todas as Formas de Discriminação Racial (1969), fez-se presente ainda, em 1978 e 1983 em duas conferências mundiais contra o racismo, e recentemente é signatário do Plano Durban 2001.

Portanto, resta claro que o princípio da igualdade cristalizado na Constituição de 1988 deixou a porta aberta para que as ações afirmativas fossem recepcionadas pelo nosso ordenamento jurídico, bem como demonstram a ratificação dos tratados e acordos internacionais dos quais o Brasil é signatário desde 1968. Dessa forma, conclui-se que existe respaldo suficiente para a implantação das medidas afirmativas.

As ações afirmativas não são necessariamente sinônimo da criação de cotas mínimas para a participação das minorias em determinados segmentos, muito embora estas em regra configuram sua efetiva atuação. Existem diversas outras maneiras da implantação de ações discriminatórias positivas capazes de promover avanço na busca da superação da desigualdade material tais como incentivos fiscais, implementos promocionais, títulos em licitações, entre outros. ${ }^{14}$

E ainda, podem ser sujeitos de ação afirmativa não só pessoa natural (física), bem como as pessoas jurídicas, pequenas empresas, empresas de propriedade de grupos minoritários étnicos, discriminados de maneira geral (como negros, e mulheres) ou especial. De fato, esses sujeitos da ação afirmativa constituem um grande todo de excluídos ou marginalizados, total ou parcialmente.

Quanto mais moderna é uma sociedade, mais rapidamente muda e age profundamente sobre si mesma e mais elimina as barreiras e as distâncias sociais do passado. (...) o apelo à igualdade de direito contra a desigualdade de fato não teria tido a força histórica que teve se não tivesse fundado sobre uma confiança absoluta no sentido de uma evolução histórica natural. ${ }^{15}$

As ações afirmativas são políticas públicas e privadas, instrumentos para implementação da igualdade material entre os cidadãos. Possuem múltiplas funções, além da promoção da justiça compensatória, ou seja, reparação de erros ancestrais, existe ainda, a promoção da justiça distributiva, promoção do pluralismo, superação de estereótipos negativos sobre afrodescendentes e, por conseguinte, o fortalecimento de sua autoestima e combate ao preconceito.

\section{LEGALIDADE DAS AÇÕES AFIRMATIVAS}

\footnotetext{
${ }^{14}$ ATCHABAHIAN, Serge. Op. cit, p. 169.

${ }^{15}$ TOURAINE, Alain. Igualdade e Diversidade: O sujeito democrático. Trad: Modesto Florezano. São Paulo: Universidade do Sagrado Coração, Edusc, Bauru, 1997, p.13.
} 
No Brasil o princípio da igualdade sempre fez parte de suas constituições. No entanto, a igualdade assegurada se aproximava muito da igualdade formal, qual seja a igualdade perante a lei. Somente com a Constituição de 1988 e a expressa previsão do princípio da igualdade no preâmbulo, bem como no Título Dos Direitos e Garantias Fundamentais, além dos objetivos fundamentais de construir uma sociedade livre, justa e solidária, garantindo o desenvolvimento nacional, erradicação da pobreza, marginalização, desigualdades sociais e regionais, bem como promover o bem de todos sem preconceitos de origem, raça, sexo, cor, idade e quaisquer outras formas de discriminação elencados no Título Dos Princípios Fundamentais concluiu-se que a igualdade formal promovia somente o nivelamento por baixo entre os cidadãos, o que implica em dizer que a igualdade (formal) estava limitada a proibir tratamento discriminatório, dessa forma, sempre existiria a desigualdade estruturalmente estabelecida. Aliado a isso houve uma mudança de pensamento por parte da doutrina e jurisprudência em sintonia com as tendências internacionais de respeito aos direitos humanos fundamentais, bem como em consonância com os valores do Estado Democrático de Direito, resgatando a verdadeira essência do ideal de justiça, surgiu uma nova percepção acerca do princípio da igualdade, qual seja a igualdade material.

\section{Segundo Hans Kelsen:}

A igualdade dos sujeitos na ordenação jurídica, garantida pela Constituição, não significa que estes devam ser tratados de maneira idêntica nas normas e em particular nas leis expedidas com base na Constituição. A igualdade assim entendida não é concebível: seria absurdo impor a todos os indivíduos exatamente as mesmas obrigações ou lhes conferir exatamente os mesmos direitos sem fazer distinção alguma entre eles, como por exemplo, entre crianças e adultos, indivíduos mentalmente sadios e alienados, homens e mulheres. ${ }^{16}$

A dicotomia do princípio da igualdade (formal e material) que ora se confunde com o binômio isonomia e igualdade recomenda especial atenção ao aplicador da lei eis que sempre estará presente pelo menos um dos princípios. O que determinará qual deles deve ser aplicado implica necessariamente em um conhecimento da realidade do caso concreto. Pois, a falta dessa visão da sociedade pode gerar mais desigualdade.

De acordo com Cármen Lúcia Antunes Rocha, Ministra do Supremo Tribunal Federal:

\footnotetext{
${ }^{16}$ KELSEN, Hans Apud SILVA, Marcelo da. Digressões acerca do princípio constitucional da igualdade. Jus Navigandi, p. 01. Disponível em: http://jus2.uol.com.br/doutrina/texto.asp?id=4143, acesso em: 28/11/2009.
} 
[...] a definição jurídica objetiva e racional da desigualdade dos desiguais, histórica e culturalmente discriminados, é concebida como uma forma para se promover a igualdade daqueles que foram e são marginalizados por preconceitos encravados na cultura dominante na sociedade. Por esta desigualação positiva promove-se a igualação jurídica efetiva; por ela, afirma-se uma fórmula jurídica para se provocar uma efetiva igualação social, política, econômica no e segundo o Direito, tal como assegurado formal e materialmente no sistema constitucional democrático. A ação afirmativa é então, uma forma jurídica para se superar o isolamento ou a diminuição social a que se acham sujeitas a minorias. ${ }^{17}$

Segundo Flávia Piovesan, o legislador constituinte teve especial preocupação com os direitos e garantias fundamentais, bem como a questão da igualdade e, por conseguinte com a implementação da igualdade substancial.

(a) "topografia" de destaque que recebe este grupo direitos (fundamentais) e deveres em relação às Constituições anteriores; (b) a elevação, à "cláusula pétrea", dos direitos e garantias individuais (art. 60, parágrafo $4^{\circ}$, IV); c o aumento dos bens merecedores de tutela e da titularidade de novos sujeitos de direito ("coletivos"), tudo comparativamente às Cartas antecedentes. ${ }^{18}$

Por estar expressamente prevista na Constituição ficava clara a preocupação do legislador constituinte com as questões sociais nacionais. E mais, para alguns doutrinadores isso implica em dizer que a igualdade material impõe um dever ao Estado de promover de fato a igualdade, garantindo aos seus cidadãos iguais oportunidades de acesso ao mercado de trabalho, saúde e educação por meio de políticas públicas e leis que compensem as desigualdades ancestralmente enraizadas. Portanto, deve ser observada a igualdade material tanto na elaboração das leis como em sua aplicação.

\section{ORIGEM DA DESIGUALDADE E O MITO DA DEMOCRACIA RACIAL}

Equivoca-se quem acredita que em 13 de Maio de 1888, com a assinatura da Lei Áurea aboliu-se a escravatura no Brasil do dia para noite.

Não houve a publicação de nenhuma outra lei posterior com o objetivo de permitir a inserção do negro ex-escravo na sociedade, diferentemente do que aconteceu com os demais imigrantes europeus do final do século XIX. Essa falta de implementação à liberdade do negro ex-escravo fez com que a gerações futuras ficassem expostas a

\footnotetext{
${ }^{17}$ ROCHA, Cármen Lúcia Antunes. Ação Afimativa: O conteúdo democrático do princípio da igualdade. Revista de Informação Legislativa, Brasília, ano 33, n. 131, julho - setembro 1996, p. 286.

${ }^{18}$ PIOVESAN, Flávia. Apud. GOMES, Joaquim Benedito Barbosa e Silva, Fernanda Duarte Lopes Lucas da. Ações Afirmativas e os Processos de Promoção da Igualdade Efetiva. Seminário Internacional - As Minorias e o Direito. Série Cadernos CEJ 24. p. 102. Disponível em: http://w3.ufsm.br/afirme/ARTIGOS/variados/var02.pdf, acesso em: 28/11/2009.
} 
um legado de exclusão social. E então, o problema que no passado se chamava de escravidão, hoje chamamos de desigualdade. ${ }^{19}$

As decisões políticas e econômicas sobre os rumos do país que sucederam a abolição da escravatura foram tomadas sem qualquer preocupação com a integração do exescravo. Sem qualquer participação na vida política, econômica e social da nação os exescravos, e seus descendentes, agora "homens livres", destituídos de terras e de bens, só podiam vender a sua mão-de-obra para garantir o seu sustento e de suas famílias.

No Brasil, aos libertos não foram dadas nem escolas, nem terras, nem empregos. Passada a euforia da libertação, muitos ex-escravos regressaram a suas fazendas, ou a fazendas vizinhas, para retomar o trabalho por baixo salário. Dezenas de anos após a abolição, os descendentes de escravos ainda viviam nas fazendas, uma vida pouco melhor do que a de seus antepassados escravos. Outros dirigiram-se às cidades, como o Rio de Janeiro, onde foram engrossar a grande parcela da população sem emprego fixo. Onde havia dinamismo econômico provocado pela expansão do café, como em São Paulo, os novos empregos, tanto na agricultura como na indústria, foram ocupados pelos milhares de imigrantes italianos que o governo atraía para o país. Lá, os ex-escravos foram expulsos ou relegados aos trabalhos mais brutos e mais mal pagados. ${ }^{20}$

Enquanto os antigos proprietários de escravos e terras valeram-se de sua força econômica e política para decidirem os rumos a serem tomados conforme seus interesses. Esse momento histórico foi tão decisivo na história do Brasil, que os ex-proprietários de escravos beneficiaram-se com os acontecimentos posteriores, o qual merece destaque o processo de industrialização do país, enquanto um imenso contingente de "cidadãos" foi abandonado a sua própria sorte.

A política brasileira, vale dizer, seus representantes, nunca se preocupou com o equilíbrio sócio-econômico no país, desenvolvendo por consequiência, uma legião de miseráveis de um lado e poucos abastados de outro. Diferentemente de muitos países, no Brasil a igualdade formal da lei, na prática está distante da realidade. ${ }^{21}$

O preconceito profundamente enraizado nas culturas nacionais de países como Brasil, Estados Unidos da América, África do Sul, os quais têm em comum um passado colonial marcado pela escravidão demonstram a resistência, ou ineficácia da igualdade formal

\footnotetext{
${ }^{19}$ CABRAL, Karina Melissa. Brasil x Apartheid Social. As Ações Afirmativas como meio para superação das desigualdades raciais $e$ de gênero. Jus Navigandi, p. 01 . Disponível em: http://jus2.uol.com.br/doutrina/texto.asp?id=6711, acesso em: 28/11/2009.

${ }^{20}$ CARVALHO, José Murilo de. Cidadania no Brasil: O longo caminho. $12^{\text {a }}$ Ed. Rio de Janeiro: Civilização Brasileira, 2009, p. 52.

${ }^{21}$ ATCHABAHIAN, Serge. Op. cit, p. 43.
} 
em razão de que no período pós-abolição legou-se aos negros posições inferiores de decisão e participação.

O matador mata sempre duas vezes - a segunda pelo silêncio. [...] Em alguns racismos conhecidos na história da humanidade, as relações entre segmentos étnicos diferentes são mais explícitas, mais abertas; é um racismo institucionalizado, por vezes acompanhado de hostilidades e da morte física do outro. Quero me referir ao nazismo, ao apartheid sul-africano, ao sistema "Jim Crow" nos Estados Unidos. Mas outros racismos foram e são implícitos, não institucionalizados, objeto de segredo e tabu, submetidos ao silêncio, um silêncio criminoso. Quero me referir, como vocês devem ter captado pela mensagem camuflada no título, ao racismo brasileiro. ${ }^{22}$

Em decorrência do processo histórico, determinados grupos foram marginalizados e discriminados não possuindo as mesmas oportunidades auferidas por outros. "A longa e histórica estabilidade da desigualdade entre negros e brancos faz com que o convívio cotidiano com ela passe a ser encarada pela sociedade como algo natural". ${ }^{23}$

Principalmente as obras de Gilberto Freyre contribuíram para a construção da idéia de um país sem preconceito racial ou fundado na cor da pele em razão de que o povo brasileiro seria produto da mistura entre brancos, negros, e índios.

\begin{abstract}
Afirmar a mestiçagem implicou, durante anos, no não reconhecimento das diversas minorias, porque se essas já estavam integradas, não se consistiam, em verdade, em minorias, logo, precisavam de tratamento diferenciado, protetivo ou de inclusão. Ao contrário, pensar em criar ações específicas em prol de determinados grupos sociais correspondia a fomentar a discriminação e a desigualdade, já que todos, no Brasil, eram, segundo a ideologia dominante, iguais por origem histórica, pela cultura mestiça e pela diversidade de identidades. ${ }^{24}$
\end{abstract}

Segundo Céli Regina Jardim Pinto, existe uma história politica no país de exclusão e reprodução dos poderes das elites.

O discurso da democracia racial é o apagamento do fato de que as pessoas negras são mais pobres, porque são negros e porque há um preconceito. Não é por acaso, não é coincidência. Não é porque são mais burros, não é porque são menos estudados. É porque quem é negro não consegue estudar, sendo negro tem menos

\footnotetext{
${ }^{22}$ MUNANGA, Kabengele. As facetas de um racismo silenciado. In: SCWARCZ, Lilia. QUEIROZ, Renato da Silva (Org). Raça e Diversidade. São Paulo: Edusp, 1996. p. 13.

${ }^{23}$ JACCOUD, Luciana de Barros, e BEGHIN, Nathalie. Desigualdades raciais no Brasil: um balanço da intervenção governamental. Brasília: IPEA, 2002, p 12. Disponível em: http://w3.ufsm.br/afirme/LEITURA/diversos/div03.pdf, acesso em: 28/11/2009.

${ }^{24}$ ANNONI, Danielle. As Políticas De Ações Afirmativas Para A Efetivação De Direitos Da Minoria Negra No Brasil. p. 03. Disponível em: http://srvapp2s.urisan.tche.br/seer/index.php/direitosculturais/article/viewFile/29/23, acesso em 26/10/2010.
} 
possibilidades de empregos. Mas isso é como apagado através da ideia de uma democracia racial. $^{25}$

O mito da democracia racial busca esconder os conflitos raciais existentes e diminuir sua importância, bem como exercer o controle sobre a população negra sem que se exerça uma violência visível, diversamente do que aconteceu nos Estados Unidos e na África do Sul. Porém, o fato de que a violência não seja visível não implica em dizer que ela não existe. O abismo social existente no Brasil está oculto na desigualdade racial e no preconceito "maquiado".

\begin{abstract}
De acordo com GUIMARÃES, o mito da democracia racial aparece como subterfúgio para explicar no Brasil uma inexistência de minorias étnicas, e o emprego da mestiçagem como sinônimo de harmonia social entre os diversos grupos étnicos brasileiros. Historicamente a utilização do termo "raça" - para definir a existência dos diversos grupos étnicos do país - foi uma proposta que partiu dos próprios movimentos negros como mecanismo de denúncia da falsa mestiçagem brasileira e do mito da democracia racial. ${ }^{26}$
\end{abstract}

Na sociedade brasileira, "têm-se a percepção de que o negro só pode ascender socialmente através do esporte e da arte. Portanto, os modelos para os negros provavelmente vêm desses dois tipos de atividades" 27 , a falta de modelos sociais influencia diretamente na formação da identidade das crianças, e ainda, a constante exposição a violência, drogas, aliada a evasão escolar, e gravidez precoce fruto da miséria em que se encontram e da falta de informação os mantém marginalizados, excluídos e com poucas esperanças ou nenhuma de mudar de vida.

A exclusão do afrobrasileiro tem sido debatida em diversas análises de natureza sociológica e antropológica, facilmente constatável a partir das simples visualização de dados estatísticos (indicadores sócio-econômicos do IPEA, IBGE, PNUD-ONU etc.).

"Estudos recentes alguns deles realizados pelo do Instituto de Pesquisa Econômica Aplicada - IPEA evidenciam as desigualdades vivenciadas pelos afrobrasileiros em todas as esferas da vida social." ${ }^{28}$ Pesquisas realizadas entre os anos de 1995 e 2002, demonstram que: apesar do crescimento econômico que marcou a segunda metade do século $\mathrm{XX}$, as desigualdades econômicas entre brasileiros brancos e não-brancos não diminuíram.

\footnotetext{
${ }^{25}$ PINTO, Céli R. J. Teorias da democracia: diferenças e identidades na contemporaneidade. Porto Alegre, EDIPUCRS, 2004. p. 35 e 36

${ }^{26}$ ANNONI, Danielle. Op cit.

${ }^{27}$ TRAGTENBERG, Marcelo Henrique Romano. Um olhar de branco sobre ações afirmativas. Revista Espaço Acadêmico. Ano II - n.13, Junho de 2002. Disponível em: http://www.espacoacademico.com.br/013/13cmtrag.htm, acesso em: 28/11/2009.

${ }^{28}$ JACCOUD, Luciana de Barros, e BEGHIN, Nathalie. Op. cit, p. 11.
} 
Inúmeros relatórios de instituições especializadas dão conta da discrepância estatística de determinados seguimentos da sociedade em relação a ocupação de cargos em estabelecimentos de ensino, especialmente de nível superior, fruição dos bens da vida, percepção salarial, entre tantos outros fatores ${ }^{29}$

O que evidencia que a igualdade resguardada constitucionalmente não é eficaz a medida que não são conferidas a todos os cidadãos as mesmas condições e oportunidades."A baixa condição socioeconômica cria um ciclo vicioso em que um enorme contingente de brasileiros fica excluído dos mecanismos de mobilidade social por não ter a escolaridade adequada às exigências do mercado". 30

No Brasil construiu-se um discurso de democracia racial, de terra livre de preconceitos, miscigenação cultural e biológica em ideais nacionais que procuravam integrar todos os indivíduos no Estado Nação. Porém, no Brasil, o racismo é diferente de outros lugares como, por exemplo: Estados Unidos, e África do Sul. Está presente nas práticas sociais e no discurso não racista, sendo negado e, por conseguinte sem o reconhecimento pelo sistema judiciário.

A partir da década de 1970 intensificaram-se as lutas pelo Movimento Negro a fim de buscar a igualdade de direitos, agindo para que as leis garantissem as mesmas oportunidades para todos, rompendo com o mito da democracia racial. Segundo o qual não existem conflitos raciais no Brasil, em razão de que toda a população é mestiça, e que o desenvolvimento econômico iria apagar os resíduos de preconceito e racismo, promovendo a inclusão da população negra. Porém, até meados de 1990 o Movimento Negro não havia conseguido espaço de atuação no âmbito estatal, principalmente porque o Estado sempre reprimiu qualquer ação que tentasse desmistificar a ideologia da democracia racial brasileira.

Com o processo de redemocratização do país pós 1980 medidas concretas foram tomadas de forma isolada, merecendo destacar-se a criação do Conselho de Participação e Desenvolvimento da Comunidade Negra em 1984, pelo governo de Franco Montoro no Estado de São Paulo, com o objetivo de desenhar e implementar políticas de inserção da população negra na sociedade.

A partir de 1980 o IBGE $^{31}$ de forma inédita publicou estudos sobre as desigualdades entre brancos e negros no mercado de trabalho. Ainda na década de 1980 foram

\footnotetext{
${ }^{29}$ ATCHABAHIAN, Serge. Op. cit, p.174.

${ }^{30}$ SANTIAGO, Nestor. Op. cit, p. 139.

${ }^{31}$ OLIVEIRA, Lucia Elena Garcia de, PORCARO, Rosa Maria, e ARAUJO, Tereza Cristina Costa. O lugar do negro na força de trabalho. Rio de Janeiro: IBGE, 1981.
} 
tombados pelo patrimônio histórico dois símbolos da cultura negra: o terreiro de candomblé Casa Branca, na Bahia em 1984, e em 1986 a Serra da Barriga, em Alagoas, sede do Quilombo dos Palmares.

Em 1987 no governo do presidente José Sarney foi criado a partir de decreto presidencial o Programa Nacional do Centenário da Abolição da Escravatura, a ser executado durante o ano de 1988, emergindo dessa forma a questão racial em âmbito nacional.

\begin{abstract}
Os trabalhos da Assembléia Nacional Constituinte no ano de 1987 foram realizados mediante a participação da sociedade civil organizada. Os movimentos negros colocaram em pauta as suas principais reivindicações, dentre as quais pode-se destacar: a) denunciar o racismo e a discriminação racial pelo qual sofrem as minorias negras brasileiras; b) denunciar a democracia racial como mito e forma de impedir o investimento em políticas públicas de ações afirmativas na luta antiracista; c) resgatar a cultura afro-brasileira por meio do reconhecimento das diversas identidades, da valorização da diversidade e do reconhecimento de uma sociedade multirracial e multicultural. ${ }^{32}$
\end{abstract}

No mesmo ano na mesma efervescência de idéias promulgou-se a Constituição Federal a qual foi batizada por Ulysses Guimarães como "A Constituição Cidadã”, a qual trouxe indiscutíveis avanços no que tange à questão racial, ao menos na esfera formal.

Destacam-se entre eles:

[...] o reconhecimento das contribuições culturais dos diferentes segmentos étnicos, considerando-as em pé de igualdade com a sociedade envolvente; a criminalização do racismo, e o direito das comunidades remanescentes de quilombos ao reconhecimento da propriedade definitiva de suas terras, devendo o Estado emitirlhes título de propriedade. ${ }^{33}$

Na segunda metade da década de 1990 a questão racial foi impulsionada por uma série de medidas do governo federal, fruto do reconhecimento do problema racial no país e da desigualdade por ele ocasionada.

Uma das alavancas desse novo impulso deve ser creditada a "Marcha Zumbi dos Palmares Contra o Racismo, pela Cidadania e a Vida", realizada em 20 de Novembro de 1995 na qual participaram milhares de pessoas em homenagem ao tricentenário da morte de Zumbi dos Palmares, ao final foi entregue ao então Presidente da República Fernando Henrique Cardoso um documento sobre a situação do negro no país e um programa de ações para a superação do racismo e das desigualdades raciais no país. ${ }^{34}$

\footnotetext{
32 ANNONI, Danielle. Op. cit, p. 04.

${ }^{33}$ OLIVEIRA, Lucia Elena Garcia de, PORCARO, Rosa Maria, e ARAUJO, Tereza Cristina Costa. Op. cit.

${ }^{34}$ Ibid., p. 19.
} 
O retrato das discrepâncias sociais no Brasil entre negros e brancos é fruto de anos de abandono por parte do Estado, e de exploração por parte da sociedade. A marginalização nas esferas econômica, social, cultural entre outras, sempre foi uma espécie de cabresto para controlar os excluídos mantendo-os acorrentados pelos costumes, ou pela necessidade, presos como engrenagens no sistema.

\begin{abstract}
O quadro de desigualdade racial apresentado neste documento revela o drama da marginalização econômica e da injustiça social que afeta os afrodescendentes no Brasil: são 76 milhões de pessoas, na sua maioria pobre; $47 \%$. Note-se que, entre os brancos, esse percentual é de $22 \%$, isto é, a metade. Com efeito, os afrobrasileiros têm mais chances de ser desempregados, e no geral costumam ganhar cerca da metade dos rendimentos dos brancos. A maior parte vive de economia informal, portanto sem acesso aos direitos trabalhistas, sem aposentadoria pública, nem auxílios em caso de doença ou acidente de trabalho. Tornado os negros candidatos a ingressarem no mundo dos pobres e miseráveis, quando já não estão. ${ }^{35}$
\end{abstract}

Conforme o Instituto Brasileiro de Geografia e Estatística - IBGE, a população brasileira é formada por $24 \%$ de analfabetos. Destes, $80 \%$ são negros. E ainda, conforme dados do Ministério da Educação dos formados em universidades brasileiras, $80 \%$ são brancos e somente $2 \%$ são negros. ${ }^{36}$

Segundo dados da Organização das Nações Unidas para Educação, Ciência e a Cultura (Unesco) “enquanto o nível fundamental público é freqüentado pelos mais pobres, o nível superior público é ocupado pelos $40 \%$ mais ricos”,37 no Brasil.

São citados vários índices que demonstram como a população negra é discriminada duplamente, primeiro por ser negra, e depois por ser pobre, pois em todos os indicadores a população negra leva desvantagem em comparação com a branca.

A pobreza no Brasil tem cor. Assim, tanto as políticas de combate à fome e à miséria como as políticas públicas de qualidade nos campos da educação, da saúde, do emprego, da habitação, da previdência social e da assistência social beneficiarão, necessariamente, a população negra. ${ }^{38}$

Não há novidade referente às estatísticas sobre a desigualdade social e econômica no Brasil. Segundo Paulo Luiz Miadaira, esta situação de exclusão social possui várias facetas e decorre "de um conjunto de relações institucionais, políticas e culturais existentes em nosso país que facilitam ou restringem o acesso às oportunidades à educação, moradia, saúde, segurança". 39

\footnotetext{
${ }^{35}$ JACCOUD, Luciana de Barros, e BEGHIN, Nathalie. Op. cit, p. 65.

${ }^{36}$ ATCHABAHIAN, Serge. Op. cit, p. 145.

${ }^{37}$ SANTIAGO, Nestor. Op. cit, p. 139.

${ }^{38}$ JACCOUD, Luciana de Barros, e BEGHIN, Nathalie. Op. cit., p. 43.

${ }^{39}$ SANTIAGO, Nestor. Op. cit., p. 138.
} 
Infelizmente, "a cor das pessoas é um determinante importante nas chances de vida, e a discriminação está presente em todas as fases do ciclo de vida individual" 40

\begin{abstract}
As desigualdades de raça/cor no Brasil constituem-se um exemplo iniludível de como cidadãos são colocados em situação de desvantagem no convívio social por motivos que ultrapassam largamente a capacidade de reação de um ser humano. Eventualmente, poderá se encontrar dados que sustentem a tese de que a longo prazo a dinâmica social dissolveria as desvantagens dos negros na convivência social. No entanto, não parece justo que cidadãos venham a arcar sozinhos com as consequiências de três séculos de escravidão, somadas a incorporação cultural das discriminações de cor. ${ }^{41}$
\end{abstract}

Todos os dados disponíveis demonstram uma disparidade de condições materiais de vida entre brancos e negros no Brasil. Aí funda-se a base da discussão sobre as políticas afirmativas nessa área, pois tratando-se desigualmente os desiguais cria-se condições de igualdade.

Quando a questão do racismo no Brasil começar a sair dos livros, artigos,
dissertações e teses de pesquisadores, quando deixar de ser problema do negro para
se tornar preocupação de todas as forças e instituições do país, quando sairmos da
fase do belo discurso e das boas intenções sem ações correspondentes, poderá dizer
então que estamos na verdadeira fase de engajamento para transformar a sociedade;
estaremos para entrar num sonho, e do sonho para entrar numa verdadeira
esperança. As discussões acerca dos problemas da desigualdade, exclusão social e do racismo devem ir além da esfera acadêmica e atingir a população em geral principalmente porque não são problemas só do negro, do pobre, da mulher, do deficiente, do idoso, do homossexual, e sim de toda sociedade. Pois, o impacto das conseqüências da exclusão já é sentido por todos.

A injustiça real impõe um novo modo de entender a igualdade, uma evolução dos conceitos de igualdade e justiça a fim de se ajustarem às concepções formais e reais ou materiais.

[...] justiça formal consiste "um princípio de ação, segundo o qual seres de uma mesma categoria essencial devem ser tratados da mesma forma." Aí a justiça formal se identifica com a igualdade formal. A justiça concreta ou material seria, para Perelmann, a especificação da justiça formal, indicando a característica constitutiva da categoria essencial, chegando-se às formas: a cada um segundo a sua necessidade; a cada um segundo seus méritos; a cada um a mesma coisa. Porque existem desigualdades, é que se aspira à igualdade real ou material que busque realizar a igualação das condições desiguais, do que se extrai que a lei geral, abstrata e impessoal que incide em todos igualmente, levando em conta apenas a igualdade

\footnotetext{
${ }^{40}$ JACCOUD, Luciana de Barros, e BEGHIN, Nathalie. Op. cit., p. 11.

${ }^{41}$ RABAT, Márcio Nuno. Princípio da Igualdade, Ação Afirmativa e Democracia Racial. Cardenos Aslegis 4(12):34-37. Set/Dez 2000, p. 01. Disponível em:_http://w3.ufsm.br/afirme/ARTIGOS/variados/var04.pdf, acesso em: 28/11/2009.

${ }^{42}$ MUNANGA, Kabengele. Op. cit, pp. 218-219.
} 
dos indivíduos e não a igualdade dos grupos, acaba por gerar mais desigualdade e propiciar a injustiça. ${ }^{43}$

Nas palavras de Nancy Fraser as teorias de justiça contemporâneas devem ser tridimensionais, ou seja, além da dimensão econômica da redistribuição, e da dimensão cultural do reconhecimento, deve-se buscar a dimensão política da representação, e esta última é capaz de suportar as outras duas.

A política é o palco onde as lutas por distribuição e reconhecimento são conduzidas. É onde se estabelecem as regras de decisão da disputa tanto na dimensão econômica, quanto na cultural.

Superar a injustiça significa desmantelar os obstáculos institucionalizados que impedem alguns sujeitos de participarem, em condições de paridade com os demais, como parceiros integrais da interação social. ${ }^{44}$

Segundo Celso Antonio Bandeira de Mello em sua obra Conteúdo Jurídico do Princípio da Igualdade a discriminação positiva, ou ainda, as chamadas ações afirmativas são plenamente possíveis, inclusive o autor proporciona ao leitor inúmeros exemplos de casos em que é possível a discriminação, desde que se possa determinar: quem são os iguais? quem são os desiguais? em que consiste a desigualdade?

Numa perspectiva rigorosamente positivista, Bandeira de Mello enfatiza que o princípio constitucional da isonomia envolve discriminações legais de pessoas, coisas fatos e situações. Discute, então, quando discrimenes se justificam sem que o princípio vetor seja deturpado. E aponta três exigências: a presença de traços diferenciais nas pessoas, coisas, situações ou fatos; correlação lógica entre fator discrímen e desequiparação procedida; consonância da discriminação com os interesses e valores protegidos na Constituição. ${ }^{45}$

Para que possam ser aplicadas as ações afirmativas sem que se ofenda o princípio da isonomia é necessário que as mesmas passem pelo crivo de três filtros, quais sejam: primeiramente o elemento tomado como fator de desigualação, depois, é fundamental que haja uma conexão lógica entre o fato erigido como critério de discriminação e a disparidade estabelecida no tratamento jurídico diferenciado, e por fim, com relação a consonância da correlação lógica com os interesses absorvidos no sistema constitucional.

\footnotetext{
${ }^{43}$ SILVA, José Afonso da. Curso de Direito Constitucional Positivo. 22a Ed. São Paulo: Malheiros Editores Ltda, 2003, p. 212.

44 FRASER, Nancy. Reenquadrando a justiça em um mundo globalizado. Lua Nova, São Paulo, n. 77, 2009. p.17.

${ }^{45}$ NEVES, Marcelo. Apud. SILVA, Luiz Fernando Martins da. Políticas de ação afirmativas para negros no Brasil: Considerações sobre a compatibilidade com o ordenamento jurídico nacional e internacional. Revista Jurídica, v 8, n 82, Brasília: dez/jan, 2007, p. 73.
} 


\section{CONCLUSÃO}

Portanto, a discriminação é fator idoneamente jurídico que permite o tratamento diferenciado (favorável) para um determinado grupo de pessoas. Desde que apresentado um vínculo de correlação lógica entre a peculiaridade diferencial acolhida por residente no objeto, e a desigualdade de tratamento em função dela.

A adoção das ações afirmativas atualmente é resultado da pressão historicamente exercida pelos segmentos excluídos da sociedade, aliadas a grandes mudanças externas e internas no pensamento jurídico, político e social. A proposta das ações afirmativas é dissolver as desigualdades fortemente arraigadas no tecido social.

Historicamente o Brasil é marcado por mais de 300 anos de escravidão. O Brasil Colonial foi construído pelas mãos dos escravos vindos da África. Em 1888 com a abolição da escravatura principalmente porque a mão-de-obra escrava não interessava aos valores do capitalismo, um imenso contingente de pessoas "livres" foi abandonado a sua própria sorte. Diferentemente dos grupos imigrantes europeus do final do século XIX a liberdade sem qualquer amparo por parte do Estado legou ao negro a exclusão social em suas mais variadas facetas, essas desigualdades entre brancos e negros nos campos econômico, social e educacional persistem até os dias de hoje marcados, sobretudo pela perversidade da sombra do preconceito racial culturalmente estabelecido.

Nesse contexto as ações afirmativas emergem como instrumento hábil capaz de resgatar a dignidade das minorias, promovendo a igualdade em sua essência rompendo com os preconceitos culturalmente estabelecidos. E por tais motivos sua implementação tem sido fruto de tantas polêmicas em escala nacional, em especial destaca-se a reserva de cotas nas universidades públicas para afrodescendentes, trazendo a tona velhas discussões sobre a questão racial na sociedade brasileira.

\section{REFERÊNCIAS}

ANNONI, Danielle. As Políticas De Ações Afirmativas Para A Efetivação De Direitos Da

Minoria Negra No Brasil. p. 03. Disponível em:
http://srvapp2s.urisan.tche.br/seer/index.php/direitosculturais/article/viewFile/29/23, acesso em 26/10/2010. 
ATCHABAHIAN, Serge. Princípio da Igualdade e Ações Afirmativas. São Paulo: RCS Editora, 2004.

CABRAL, Karina Melissa. Brasil x Apartheid Social. As Ações Afirmativas como meio para superação das desigualdades raciais e de gênero. Jus Navigandi, p. 01. Disponível em: http://jus2.uol.com.br/doutrina/texto.asp?id=6711, acesso em: 28/11/2009.

CARVAlHO, José Murilo de. Cidadania no Brasil: O longo caminho. $12^{\mathrm{a}} \mathrm{Ed}$. Rio de Janeiro: Civilização Brasileira, 2009, p. 52.

FRASER, Nancy. Reenquadrando a justiça em um mundo globalizado. Lua Nova, São Paulo, n. 77, 2009.

GOMES, Joaquim Barbosa e SILVA, Fernanda Duarte Lopes Lucas da. Ações Afirmativas e os Processos de Promoção da Igualdade Efetiva. Seminário Internacional - As Minorias e o Direito. Série Cadernos CEJ 24, p. 20. Disponível em: http://w3.ufsm.br/afirme/ARTIGOS/variados/var02.pdf, acesso em: 28/11/2009.

JACCOUD, Luciana de Barros, e BEGHIN, Nathalie. Desigualdades raciais no Brasil: um balanço da intervenção governamental. Brasília: IPEA, 2002, p 12. Disponível em: http://w3.ufsm.br/afirme/LEITURA/diversos/div03.pdf, acesso em: 28/11/2009.

MELlO, Celso Antônio Bandeira de. Conteúdo Jurídico do Princípio da Igualdade. $3^{\mathrm{a}}$ ed. São Paulo: Malheiros, 2008.

MUNANGA, Kabengele. As facetas de um racismo silenciado. In: SCWARCZ, Lilia. QUEIROZ, Renato da Silva (Org). Raça e Diversidade. São Paulo: Edusp, 1996. pp. 213229.

OLIVEIRA, Lucia Elena Garcia de, PORCARO, Rosa Maria, e ARAUJO, Tereza Cristina Costa. O lugar do negro na força de trabalho. Rio de Janeiro: IBGE, 1981.

PINTO, Céli R. J. Teorias da democracia: diferenças e identidades na contemporaneidade. Porto Alegre, EDIPUCRS, 2004.

RABAT, Márcio Nuno. Princípio da Igualdade, Ação Afirmativa e Democracia Racial. Cardenos Aslegis 4(12):34-37. Set/Dez 2000, p. 01. Disponível em: http://w3.ufsm.br/afirme/ARTIGOS/variados/var04.pdf, acesso em: 28/11/2009.

ROCHA, Cármen Lúcia Antunes. Ação Afimativa: O conteúdo democrático do princípio da igualdade. Revista de Informação Legislativa, Brasília, ano 33, n. 131, julho - setembro 1996.

SANTIAGO, Nestor Eduardo Arruna. NORBERTO, Aurilena Pereira. RODRIGUES, Sandra Maria Coelho. Direito à inclusão: implantação de políticas de ações afirmativas na IES públicas brasileiras - experiência na UFC. Pensar, v.13, n.1, Jan/Jun, 2008, p. 138. Disponível em: http://www.unifor.br/notitia/file/2554.pdf, acesso em: 28/11/2009. 
SILVA, José Afonso da. Curso de Direito Constitucional Positivo. 22 ${ }^{\text {a }}$ Ed. São Paulo: Malheiros Editores Ltda, 2003.

SILVA, Luiz Fernando Martins da. Políticas de ação afirmativas para negros no Brasil: Considerações sobre a compatibilidade com o ordenamento jurídico nacional e internacional. Revista Jurídica, v 8, n 82, Brasília: dez/jan, 2007.

SILVA, Marcelo da. Digressões acerca do princípio constitucional da igualdade. Jus Navigandi, p. 01. Disponível em: http://jus2.uol.com.br/doutrina/texto.asp?id=4143, acesso em: 28/11/2009.

TOURAINE, Alain. Igualdade e Diversidade: O sujeito democrático. Trad: Modesto Florezano. São Paulo: Universidade do Sagrado Coração, Edusc, Bauru, 1997.

TRAGTENBERG, Marcelo Henrique Romano. Um olhar de branco sobre ações afirmativas. Revista Espaço Acadêmico. Ano II - n.13, Junho de 2002. Disponível em: http://www.espacoacademico.com.br/013/13cmtrag.htm, acesso em: 28/11/2009. 